\title{
PROBLEMAS DA \\ LENGUA GALLEGA
}

DOI: 10.17075/fmfhv.2021.006

Texto inédito en vida do autor, sen datar. Por algúns trazos lingüísticos significativos semella temperán, entre os anos 40 e os primeiros anos 50 . Viu a luz por primeira vez, con lixeiras adaptacións gráficas, na Antoloxía de Aquilino Iglesia Alvariño publicada polo Departamento de Filoloxía Galega da Universidade de Santiago de Compostela co gallo do Día das Letras Galegas 1986, dedicado ao autor (pp. 165-172). Arquivo familiar. 



\section{INTRODUCIÓN PESIMISTA}

Non sei si pecaremos de pesimistas si decimos que a lengua gallega vai quedando reducida a unha curiosidá lingüística e a un argot de labradores e mariñeiros.

Dá non sei qué decil-o, pero é así. I-é cousa grave, estando como estamos seguros da esistencia dunha cultura gallega superior que ninguén pode representarse sin unha lengua como sostén. Pero a verdá é que na hora de hoxe a lengua gallega solo nunha parte moi insinificante é espresión elevada de cultura. I-esto quere decir duas cousas: que por un lado a cultura gallega vive estancada e dormente, e que por outro, os poucos e escollidos, os «bos e xenerosos» da canción, apáñanse como poden pra ir traducindo noutras lenguas, inda que seña â forma de pseudomórfosis tristes e valeiras, o que en altos espíritos é imperativo sin volta.

Os meirandes representantes da nosa cultura do XIX e do XX son-o en traduciós. Mellores ou peores. Sempre en traduciós. E refírome tanto ôs que escribiron noutras lenguas como ôs que o fixeron en gallego. Xahora que hai esceuciós, das que falarei outro día — algús poemas de Rosalía de Castro, de Pondal-, pero que confirman aínda mellor o que levo dito.

No XVIII pasounos por vez derradeira o sol pol-a porta. Daba xenio baixar ôs vales do Ribeiro, do Rosal e do Salnés, do Valadouro e de Mondañedo, presididos de pazos e ciprestes e buxos vinculeiros. Daba gusto subir ôs de Montenegro e Trasdeza, Melide e a Ulloa. Mail-os pazos fidalgos quedaron nas maus de maiordomos e caseiros. Todo o señorío marchóu pr'âs vilas de rúas limpas e vivir doado. Con eles marchóu unha forma superior de vida da que moito cabería esperar e que ten o seu outono delorido nas páxinas de Valle-Inclán e da Condesa de Pardo Bazán. I-esa forma superior de vida deixóu de ter espresión na lengua velliña de Galicia pra mal traducirse noutras lenguas. A vila gallega foi entón, no remate das longas carreteras borbónicas, a tradución triste da ciudá 
moderna, chea de preocupaciós urbanísticas, sanitarias, municipales. Abríronse universidades, institutos e normales. Nelas os últimos fidalgos vidos a menos escondían coma unha vergonza máis a lengua do pazo montañés ou ribeirán. E coa lengua foron escondendo a súa i-alma. Logo por Galicia adiante foise estendendo esa bachilería libresca e pedante, da que se salvaron apenas media ducia de almas atormentadas, os Precursores.

Coa lengua de fora viñéronlle ideas de fora. I-esas ideas, sin o lévedo das nativas — afogadas coa lengua - que as fixese fecundas, esmagoreceron serodias no verso, na novela, no teatro, no ensaio político, esquencido todo antes de nacere.

Co absentismo fidalgo a lengua gallega perde toda nobre resonancia, i-é apenas a lengua do sacho e do arado, do remo i-a traiña. O maeso e o maxistrado, o abade e o político falan noutra lengua. E tras deles, o barbeiro da vila e o mozo de mostrador da tenda de sedas e de roupas brancas.

I-o peor: Tívose esto por un adianto.

E así vai tirando esta lengua velliña, da que nunca se deu leución en ningunha escola, tan libre, bela e silvestre coma as xestas das touceiras. Así vai tirando esta lengua que falan máis de dous millós de gallegos, pero que non soletrean dous mil, que apenas si a lerán douscentos, que con moito traballo escriben non máis de vinte. Así vai tirando ô longo das silveiras e das corredoiras, nos campos das feiras, ô redor das ermidas e das fontes.

Cando un poeta gallego sinte a lei da terra e se pon a cantar na fala que aluma o seu sentir, ten coma un non sei qué de recelo en despecha-los labios, e, coma pra disculparse, dinos: «e n'habendo aprendido noutra escola que na dos nosos probes aldeáns».

Ese poeta é Rosalía de Castro.

Sant'Yago de Galgao 


\section{O GALLEGO QUE SE FALA}

O que levamos dito é do gallego como lengua escrita. Frente ô que dixemos preséntase esta realidá.

Hai moito tempo que se ven decindo que Galicia ten dous millós e medio de habitantes. Zarrada a emigración, hoxe debe ter máis. As ciudades aparecen con menos, con moito menos de 500.000, inda que contemos coas vilas de terceira categoría e coas vellas ciudades ruralizadas. O que queda é campo, aldeas e máis aldeas, nas que non se oi outra palabra en castellano que as que o cura padrica na tribúa e o maeso badúa na escola pra insiñar o sistema métrico decimal.

Temos así dous millós de habitantes falando en gallego, que non ôn falar máis que en gallego, cos que conta esta lengua pra ir vivindo moitos anos.

Dixemos dous millós, e abondaría pra non temer pol-o falacio dos gallegos, vello coma os camiños. Pro a verdá é que as ciudades falan tamén gallego nas súas tres cuartas partes pol-o menos. As rúas dos oficios resonantes de martelos e zocos e boureo, falan en gallego. $\mathrm{E}$ as prazas, e os tenderetes de mercado, e a taberna escura e avafante. Cando se abren as portas das frábicas de Vigo, da Cruña e do Ferrol, a alegría do fin de xornada vértese na misma fala das mallas e esfollas. Solo no café de sillós renchidos e vidros relumbrantes, no casino escanastrado, no club deportivo e mozo, no gran comercio de telas caras se vai facendo raro o gallego.

Resulta así que o gallego é a lengua máis ou menos única dos nove décimos dos gallegos, contando ciudadanos e opidanos. Con todo, non é máis que a lengua do remo e do sacho, do reteleo de pescas e tendeiras, labregos e feireantes. O castellano colleulle a aución en todol-os centros vivos da cultura e conta cos esteos máis fortes: a escola, a adeministración, a iglesia, a escritura. Figurádevos o que é que toda Galicia aprenda a ler e a escribir en castellano, pague as pagas e se aliste no servicio castellano, rece en castellano e lea oito diarios do país en castellano. Ninguén podería crer que despóis de ser bombardeado o gallego deste xeito por máis de catrocentos anos non tivera xa sido barrido de vales e outeiros e [moito] máis dos núcreos urbanos, centros da política e da adeministración.

E non é así. Como fala natural penso que ainda vai ganando aución, debido â fecundidá tradicional das nosas mais, a falla de emigración, e sobre todo â marea de labregos que a guerra e os novos tempos botaron â vila e campan nela cos seus cartiños novos e o seu gallego que inda no tiveron tempo de cambear. 
Por eso, a súa situación é triste. O caso da lengua gallega é o de unha lengua sin emparo ningún dos recursos que poden manter a unidá das lenguas máis débiles. É o de unha lengua pra o noso caso dialeutal, sin esa gran coluna de todal-as lenguas que é a escritura. En Galicia, onde se escriben todol-os días tantas cartas âs cinco partidas, non se escribe ningunha en gallego, nin se fai en gallego ningún testamento, partilla nin obriga.

É por outro lado unha lengua sin literatura autuante fora das minorías, inda que se fagan nun ano duas ediciós de luxo de Rosalía de Castro. Sólo O Gaiteiro de Lugo, un almanaque de gran tradición e mínimo empeño literario, se pode decir que é lido estensamente por toda Galicia, como noutro tempo se ten lido o Catecismo do Labrego de Valentín Lamas Carvajal.

Agora ben. A falla destes resortes, e sobre todo, a que lamentamos ô premeiro, de unha burguesía culta que prestixie o gallego — bases nas que se ergueron todal-as lenguas modernas de algún aquél- fai que o gallego leve moitos anos esmigallándose en dialeutos sin fin, seguindo neso unha das tendencias máis constantes das lenguas. O lingüista que hoxe atravese Galicia ten a sensación de que o gallego está dividido nun formigueiro de lenguas especiales nas que o barallete é unha máis, e o Latín dos canteiros, outra. Case se pode decir que cada aldea ten a súa lengua: un vocabulario propio, unha morfoloxía propia e unha fonética da súa casa. E non digamos falacios ou maneiras de falar. Un estrumento tan común coma o sacho, chámase que eu seipa, sacho, raño, gadaño, jadaña, espicaña. Indo de Lugo a Ferrol, pasando por Ourense e Pontevedra, o que en Ribadeu eran maus, pasa por maos, maos, mans e mâs. Na misma aldea oise decir diume, deume e doume.

Este acantonamento é un resultado fatal das lenguas sin escritura. Ben [din?] alí: as palabras lévaas o aire. Pero en Galicia, minifundista en todo, moito máis.

\section{O CASTRAPO}

Poidera pensarse do que levamos dito que os gallegos, cunha lengua esmigallada en dialeutos e baralletes, non se entendían. Mais sí. Os gallegos enténdense a medio verbo e tamén se entenden falando. Pero esto non se fai senón con algunha perda. Perden o que a lengua ten de especial en cada sitio e fálase unha 
lengua que é unha media gris, sin caráuter apenas, que se distingue na concencia dos mismos que o falan por non ser gallego. Se falades con calquera ribeirao da Cruña ou de Vigo diravos que alí non se fala gallego. A vida de relación máis intensa das costas require máis a miúdo desta lengua común na que se dí hoy e temprano e indiciones. É visto que se engañan. Eles falan tamén gallego, igoal que os de Lugo e Ourense, que son a norma de ben decir e de mal facer. E teñen tamén o seu barallete de xentes de mar, con metáforas de olas e ventos, de velas e remos, que non sei. Pero o que é verdá e que eles e todol-os que salen da aldea falan unha lengua que non é pura, que perdeu aqueles repeniques que lle daban tan ben, que perdeu a salsa e o zume e non sona a gallego de adrios e feirós. É o gallego común que humorísticamente chaman castrapo, o que hoxe fala a xente moza e a vella que saliu da súa casa e andivo pol-o mundo, o que impoñen as necesidás económicas de hoxe, que saliron xa do circo estreito da aldea.

O gallego limita co portugués e co castellano. Co portugués ten unha fronteira. Sin ter feito un estudio do caso, penso que non é outra que a do estado portugués. A teima das xentes dun lado e outro do Miño, nacida xa nos tempos de $\mathrm{D}^{\mathrm{a}}$. Urraca e $\mathrm{D}^{\mathrm{a}}$. Teresa; o pouco prestixio que o portugués goza no medio común detén a brillante lengua dos Lusiadas na raia do seu país, sin que lle valla pra nada a súa relumbrante teoría de líricos saudosos.

Co castellano é outro cantar. Non hai raia política nin económica. E se non queremos falar con estricta propiedá, tampouco lingüística. $\mathrm{O}$ castellano fálase nos gobernos civís e diputaciós; nos untamentos e sindicatos; nos púlpitos e xuzgados; detrás das reixas do confesionario e detrás dos ventanos de ferrocarrís, de correos, telégrafos, teléfonos, bancos, teatros, cines. Fálase o castellano na escola, no instituto, na universidá, no coartel. O castellano é a lengua da emigración e da vida moderna, dos rezos de cada día, do diario de todal-as mañás. É a lengua prestixiada pol-a presencia dos altos funcionarios e señores e unha gran literatura de belas maxinaciós. Ninguén prescinde dela totalmente tan pronto como bota o pé fora da porta. Deste xeito, Galicia vive hoxe nun estado de bilingüismo a medias, no que non é capaz de espresarse nas dúas lenguas pero si de entendel-as e mestural-as cando ten necesidá.

Resultado desto é que a lengua gallega, ô longo de catro siglos, foi recibindo sin darse conta unha gran cantidá de palabras castellanas que van en aumento de día en día nos medios máis evolutivos. Toda a vida moderna vértese hoxe en 
vocabulario castellano. I-éste, no medio do gallego, fai logo a súa labor de erosión. Hai sufixos gallegos que están xa en período de indecisos e na lengua común se dan por mortos. E como non hai nada que poña freno a todo esto e a vida vai pra diante, a lengua común de Galicia é cada vez menos pura.

Pero o que non se quere decir é que non seña gallega, nin que Galicia no fale gallego. Fálao, como dixemos, na súa case totalidá. O que sí, este gallego común de xateiros e bestilleiros, cordeiros, cribeiros e parafuseiros, este gallego das bisbarras mariñeiras e dos arrabaldos da ciudá, é un gallego que pol-o de agora non é mel nin é fel, un falar desorado e sin gracia, unha cadea de concesiós que a lingua del cuore foi facendo â lingua del pane, como din os italianos. E o castellano de pequenos funcionarios e mozos de mostrador fino, maesos de aldeas e metrolas non sal máis ventaxoso na súa pureza tampouco. Duas lenguas non poden vivir en contauto sin desgastes de unha e de outra. Este castellano é tamén un castellano de Galicia, moito máis laido que canto se poida falar. Sendo eu neno un inspeutor da escola nativo de León fixo e repartíu un folletín coas principales incorreuciós que cometen os que en Galicia falan en castellano. O resultado foi o desta cras de bragueiros ortopédicos. O castellano de Galicia seguíu sendo un compromiso entre a lengua oficial e [a] natural, chegando a un alto grado de pureza sólo en contados casos de cultura superior. Así que o que sal triunfante e hoxe ten máis posibilidás é o gallego común, nacido nos camiños reás de Galicia, no patín do mesón maragato, nas idas e vida a América, nos coartos de guardia do coartel, nas tabernas do porto, nas segas de Castilla, no xuzgado de premeira istancia, en todol-os puntos de contauto eficaz das duas lenguas.

É lixeiro e ledo este castrapo, doado, chistoso e procaz, e Dios sabe os camiños que lle están agardando.

\section{O GALLEGO DOS ESCRITORES}

Dixemos que o gallego non é unha lengua escrita, e nunca dixemos mellor verdá. Pero referíamonos, é visto, â lengua común, â que fala todo o mundo, o mismo â que se chapurra na taberna do porto que â que se escurece no fondo de vales e caivancas nas mil aldeas de Galicia, inda que señan ben pouco amitantes. 
Non. O gallego non é unha lengua escrita. E ahí está o seu peor mal, como dixemos tamén. Pero esto non quere decir que o gallego non seña unha lengua literaria. Non quere decir pol-o menos que non haxa unha lengua literaria gallega. Por lengua escrita entendemos a espresión escrita en cartas, diarios e documentos da lengua de todol-os días. E a lengua literaria case nunca é eso. A lengua homérica non foi nunca lengua común de cada día. Nin o latín de Cicerón tampouco. Foron, eso sí, lenguas literarias, estupendos baralletes de outros tempos. I-é que unha lengua común, o caso do noso castrapo, vamos a un decir, nacido do uso e pra o uso común, non pode, sin máis, espresar senón estados vastos i-elementales. E á un home de letras que ten algo máis que decir, faille falla unha lengua que poida espresar o que hai de novo e auroral na súa i-alma. Hasta pode chegar a ser un argot de escola e cenáculo de iniciados, xa que é sabido que toda forma de arte un pouco personal nin chega nin pode chegar ô común da xente. E aquí está a cruz e o calvario do escritor gallego.

Pra os poetas non hai maior dificultá cando o son. Escriben sempre pra minorías, e o mismo cabe o gallego de Rosalía, cheo de castellanismos, que o de Manuel Antonio, enventado adrede pra os seus poemas, ou o de Leiras Pulpeiro todo entrambilicado de ruralismos localistas que solo entenden os seus paisanos de Mondañedo. Voa por riba das palabras un pô sotil de algo divino que todo o clarea.

No que se enxanga o gallego literario é na prosa, que é donde o cocho recacha o rabo, que é, quero decir, o quid en que tropezan todal-as lenguas.

O novelista gallego atopouse con todol-os problemas que levo apuntados. Por un lado a lengua da súa aldea, rica de espresiós, de metáforas, de color, pero especial por demáis, por demáis zarrada; manca noutro sentido pra decir todo o que un escritor pode querer decir. Por outro lado atópase cun gallego común, [des] colorido e desorado que n'aprecian os mismos que o usan. Únase a esto o afán de todo escritor gallego de dar a Galicia unha lengua nobre, capaz de decir algo máis que as sabidas malicias de contos de abades, e témol-os datos que precisamos pra espricar todal-as dificultás en que os prosistas gallegos se [debat]en e os pecados de que se lles acusa.

Acúsaselles de falsificadores do idioma e de inventores de argot que ninguén entende. As acusaciós salen de dous bandos: de xente de cultura lingüística elemental que non entende máis que o gallego medio que chamamos castrapo, ese 
gallego pouco máis ou menos que estades escoitando, e de auténticos lingüistas que teñen acotado xa o seu campo de estudios, conocen máis ou menos ben as formas vivas e históricas do gallego e doilles que se turbe con creaciós máis o menos fertunadas un estado de cousas que pra eles é sacrosanto.

Pode ver un cego que os premeiros non teñen ningunha razón. Unha lengua literaria non ten por qué ser unha lengua común. Pero os segundos téñen-a a medias. Non-a teñen cando se opoñen a toda creación. Eso é o mismo que condenar ô escritor á non escribir, que antes require crear un instrumento capaz. Pero téñen-a cando non ademiten certas creaciós bárbaras e desafalazadas. Os escritores gallegos, a verdá seña dita, teñen feito moitas meas sin conda. Nados en medios filocastellanos, homes de carreira todos, non poideron penetrar o xenio íntimo da lengua moitas veces, escondido nas mil voltas e reviravoltas que ten unha lengua. Hai, craro está, esceuciós. López Ferreiro e Lamas Carvajal entre os vellos, Castelao e Vicente Risco entre os novos, serán sempre exempros de fieldá á unha lengua i-escritores que se lerán con gosto.

Outros non chegaron á tanto, sin que por eso os ame menos. A lengua n'eles é postiza. Todo o seu empeño está posto no máis doado, o vocabulario. Cunha vixilancia de Argos tristes non deixan pasar palabra que ula de lonxe a castellano. Teñen bos servidores pra eso nos dicionarios gallegos, onde se almacena, en montón, moito gallego histórico, algo vivo e un pouco trabucado. Sírvelles tamén a gramática histórica, pra facer gallego histórico, eso é, pra crear novas palabras tomadas do castellano apricándolles as leises do gallego histórico, sin se decataren que esas leises teñen períodos de vixencia fora dos que non rixen. A Unamuno poñíao fora de sí ver a escritores cultos que sometían o Latín ôs mismos tormentos ou peores que o sometían os monteiros de Carriarico. Este coidado do vocabulario, cun abandono que non sei da sintaxis, levou a moitos â creación de unha lengua disvurciada das que levamos estudiado. Algús chegaron a este resultado pol-a acumulación de ruralismo, mesturados, mazados, amacicados, macizados coma seixos. Outros pol-o procedimento máis doado do dicionario e da gramática histórica, mellor ou peor entendida. A us e outros, con todo, nunca se lles pagará abondo o que pol-o gallego levan feito, as finuras de alma que lle llevan sacrificado, a fé i-a devoción que lle levan dedicado. Esto é o que nunca verán os lingüistas castellanos. 


\section{FUTURO DA LENGUA GALLEGA}

Doume conta que si é verdá todo o que levo dito, non é pra ter moito d'ollo no futuro da nosa lengua. ¿Pero quén sabe as voltas que dá o mundo?! O que non foi hoxe nin onte pode ser mañá.

O gallego é hoxe unha lengua acantonada nas caivancas de mil aldeas, bastardeada nos vagós de terceira e nas encrucilladas das rúas, gazmeante ainda na nosa novela, espulsada da política e da adeministración. Pero todo esto non é pra quitar as esperanzas. A Iliada e a Odisea non se escribiron na lengua dos grandes señores jónicos i-eolios. Nin a Mireia na lengua do xefe da xendarmería.

É verdá que en Galicia hai oito diarios en castellano e ningún en gallego, pero non lle fan ô gallego tanto mal como puidera pensarse. Entre os oito non pubrican máis aló de 50.000 números que non chegan âs verdadeiras fontes do gallego. Neste sentido é ben máis de notar o caso de O Gaiteiro de Lugo, o almanaque de que xa faléi, que se lé detrás do lume en todal-as lareiras de Galicia, e que pode dar esperanzas ôs máis desesperanzados. Quedan outros peligros, xa se sabe, e xa quedan lumbrados no que levo dito, pero de calquer xeito hai gallego e gallego aínda pra moitos anos. E como mentras hai mal hai remedio, penso que aínda lle ha de chegar a hora a esta lengua tan velliña velliña e tan nova, na que agardan tantas auroras que xa son ouros melancólicos nas súas veciñas.

De algús anos a esta parte, púxose de moda a historia gallega, o seu arte e folklore. ¿Quén nos dí que non lle ha de chegar a hora â lengua tamén? Hai hoxe institutos dedicados â investigación histórica de Galicia. O día que se estendera máis o seu campo, e non fai falla moito, incruirase a lengua gallega nas súas autividás. A lengua portuguesa, de eleución entre as que obriga o pran de enseñanzas de algús centros, chamarase daquela lengua gallega, como se debe chamar, i-entón poderá ter ô frente un profesor namorado dela. Todo esto levará á poñer na nosa Facultá de Historia unha cátedra de lengua gallega, que ha de servir a todol-os que queiran traballar sobre Galicia, documentada na súa maior parte en gallego. E o día que todo esto esteña feito, e non vexo por qué ha de tardar en suceder, teremos dado un gran paso.

O definitivo, con todo, darase cando apareza o gran escritor de Galicia. Temos e tivemos moitos e grandes escritores, pero fáltanos ainda o escritor. $\mathrm{O}$ escritor é ese ordenador que teñen â cabeza todal-as lenguas. $\mathrm{O}$ escritor de 
Galicia ha de vir, coma un rei antigo, acuñará co seu sello todo este gallego señorial e municipal acantonado. Darálle o valor do seu xenio e marcarálle o precio a que debe ser ademitido. Portugal tivo este escritor no período pre-filipino. Italia tívoo centos de anos antes da súa unidá e independencia.

Cando pasemos pol-as nosas aldeas, debemos mirar ben de todol-os recantos das silveiras.

¿Quén sabe se quedará alí escondido o noso Dante e o noso Camões? 